\title{
More Than Just Learning Discipline Skills: Social Interactions in Science Fieldwork Could Enhance Student Well-being and Cognition
}

\author{
Matt Carew ${ }^{\mathrm{a}}$, Susie $\mathrm{Ho}^{\mathrm{a}}$, and Rowan Brookes ${ }^{\mathrm{b}}$ \\ Corresponding author: matt.carew@monash.edu \\ ${ }^{a}$ Faculty of Science, Monash University, Clayton VIC 3800, Australia \\ ${ }^{\mathrm{b}}$ Faculty of Business and Economics, The University of Melbourne, Melbourne VIC 3053, Australia
}

Keywords: science fieldwork, higher education, student perceptions, social interaction

\begin{abstract}
Fieldwork is typically used to develop students' technical skills in a range of scientific domains. Fieldwork may also be particularly conducive for enhancing social learning because of increased opportunities for social interactions. However, few studies have explored the value of students' social interactions during science fieldwork. This pilot study used a mixed-methods survey to investigate 107 undergraduate students' perceptions of science fieldwork. Participants had completed science subjects with repeated on-campus fieldwork. The survey questions examined students' perceptions of the potential influence on their well-being and cognition.

Most respondents reported long-lasting benefits to their well-being (57\%; 42 students) and/or cognition (69\%; 52 students). Commonly reported benefits related to well-being included enhanced enjoyment, relaxation, increased motivation and engagement, and stress reduction. In examining cognition, commonly reported benefits included gaining a deeper conceptual understanding from 'hands-on' activities and improved information retention. Whilst a variable response rate must be considered in interpreting our findings, our preliminary results suggest science fieldwork has a broader value to learning and the student experience. Students recognise that the benefits of fieldwork activities extend beyond the development of technical skills. Future studies could further explore how science educators can generate more effective social interactions during fieldwork-based education in science.
\end{abstract}

\section{Introduction}

Social interactions during teaching and learning provide a broad range of benefits to students. In this study, we broadly define "social interactions in education" as verbal interactions between students and peers or staff (Cotton, 2009; Dunphy \& Spellman, 2009), to allow exploration of a range of benefits. A range of benefits have been documented in many domains, including psychology and sociology research and Australian government education reports (Liff, 2003; Umberson, Crosnoe, \& Reczek, 2010; Department of Education and Training [DET], 2016). Typically, educational studies on the potential benefits of social interactions have focussed on skill development and academic performance. The broad definition of "social interactions" was taken in this study to allow further exploration of other potential benefits. Of particular interest were potential diverse benefits to mental and physical well-being, given suggestions of such benefits in several studies and reports on tertiary education programs (Chanson, 2004; Fleischner et al., 2017; Kent, Gilbertson, \& Hunt, 1997). For example, The Australian Student Wellbeing Framework (Education Services Australia [ESA], 2018) reports that when students feel connected to others and experience safe and trusting relationships, their well-being and learning outcomes are enhanced in a range of ways. Social interactions can improve attendance rates and student-staff rapport (Ingholt et al., 2015; Umberson, Crosnoe \& 
Reczek, 2010). Social interactions have been shown to develop a range of transferable skills, such as teamwork, communication and interpersonal skills (Australian Curriculum, Assessment and Reporting Authority [ACARA], 2020; Kent, Gilbertson \& Hunt, 1997). They are also reported to have positive effects on student engagement, information retention and confidence (Boyle et al., 2007; Scott et al., 2012). Student well-being is currently a topic of high interest given increasing reports of mental health issues in higher education. For instance, Gallagher (2015) found that between 2010 and 2014, 94\% of US college counselling centres reported increased proportions of students with severe psychological problems, while $89 \%$ reported increased rates of students with anxiety disorders. Research into the value of social interactions in the context of well-being and mental health in higher education is clearly important.

\section{Social interactions in undergraduate science fieldwork}

While the value of social interactions is well established in the education literature, there are limited studies on this topic with an undergraduate science context (examples include Fleischner et al., 2017; Peacock, Mewis, \& Rooney, 2018). Fieldwork is defined in this study as supervised activities that take place outside of the classroom (Kent et al., 1997). Several past studies in education have established the value of fieldwork as a teaching tool, particularly in science domains (examples include Chapple, Weir \& San Martin, 2017; Kuchel, Wilson \& Ellis, 2015; Smith, 2004). Scholarly discourse on fieldwork has typically focussed on approaches for developing employability and technical skills. However, Da Silva (2014) and Fleischner et al. (2017) argue that the science fieldwork environment could be particularly conducive to effective social interactions and socially-enhanced learning, such as peer-to-peer learning. They postulate that the less formal environment may facilitate more dynamic and natural social interactions between students and peers or staff.

The available literature, while limited, appears to suggest that science undergraduates may recognise the value of social interactions during fieldwork. However, the reasons for this are less clear. In most fieldwork studies where this perception among science students is noted, this finding is tangential to the main focus of the study and is therefore left underexplored (for examples see Cotton, 2009; Dunphy \& Spellman, 2009; Kuchel et al., 2015). When evaluating pedagogy, it is necessary to consider students' perceptions on what influences their learning and attitudes towards learning (Bandura, 1986; Burney, 2008). As a result, this preliminary study seeks to first understand students' perceptions of their social interactions during science fieldwork, and how they attribute value to these fieldwork activities.

Across disciplinary domains, fieldwork has reported benefits to students' well-being. This study defined well-being as mental, emotional and physical health and wellness (ESA, 2018). In studies examining non-science domains, students perceived that social interactions positively influenced their enjoyment, motivation, engagement, and group bonding (Chanson, 2004; Hodgson, Bearman \& Schneider-Kolsky, 2012). In support of this, Edwards, Hershberger, Russell and Markert (2001) reported that frequent social interactions facilitated development of students' social ties and support networks, which is known to benefit students' mental and emotional health (ESA, 2018). Additionally, these well-being benefits could also have positive flow-on affects to student cognition. This study defined cognition as learning experiences, outcomes or abilities (Goulder, Scott, \& Scott, 2013). Rayner (2014) posits that pedagogies promoting critical thinking skills are primarily based around encouraging students to interact and participate in academic dialogue. Positive interactions can improve student cognitive outcomes, such as information retention and linking knowledge with related concepts. This has been shown in both science fieldwork and non-science contexts (for examples see 
Burney, 2008; Fleischner et al., 2017; Scott et al., 2012). Positive student-staff interactions can have a long-term positive influence on students' motivation and commitment to produce highquality work (Cotton, 2009; Hodgson et al., 2012). However, while these studies provide preliminary evidence of benefits to well-being and cognitive outcomes, further nuanced research is needed to understand the mechanisms behind these benefits, particularly in a science context. Gaining students' perceptions can be valuable in this area.

From the non-science literature discussed above, we can infer that there are many potential benefits of social interactions in fieldwork. The lack of studies in the specific context of science undergraduate fieldwork presents a unique opportunity for further research. Refining our understanding of the mechanisms behind such benefits could be useful in pedagogy and curriculum design. This preliminary study focussed on an undergraduate biology cohort to investigate science students' broad perceptions of their social interactions during fieldwork activities. More specifically, this study aimed to investigate student perceptions of how social interactions during fieldwork affected their well-being and cognition. During this study we explored the following:

1. What are the dominant reasons that science students value social interactions during fieldwork activities?

2. Do science students perceive that social interactions during fieldwork activities benefit their well-being, and why?

3. Do science students perceive that social interactions during fieldwork activities benefit their cognition, and why?

\section{Methods}

This study used a mixed-methodology approach (Sadan, 2014). We created a novel survey (non-validated). The design drew upon one primary theory and was informed by formats from various validated survey instruments (Bandura, 1986; Cotton, 2009; Dunphy \& Spellman, 2009; Peacock et al., 2018). Likert-scale (Likert, 1932) and yes/no questions were followed by open-response questions to allow a more nuanced interpretation of the quantitative data. A human ethics application was completed and approved by the Monash University Human Research Ethics Committee in November 2018 (MUHREC Project ID 17506).

\section{Theoretical framework}

Social cognitive theory (SCT) formed the main theoretical framework for the survey design because it recognises principles of social learning. SCT claims that an individual's decisions or actions are dependent on their own perception of their efficacy, as influenced by social learning (Bandura, 1986). SCT states that an individual's perception of themselves in a social environment may either support them in behaving optimally, or impede them by placing constraints on their actions. Expanding on this, SCT also addresses how a student's perception of themselves in a group, in terms of their social status or their role in groupwork, can affect their engagement or learning (Anderson, Thomas \& Nashon, 2009). SCT has been applied in previous education studies due to its applicability to both individual and group-based learning outcomes (for example Burney, 2008). SCT is similarly applicable to this study of students' perceptions of feelings or behaviour during fieldwork that may influence learning and the student experience. 


\section{Questionnaire design}

A unique survey was created for this study, drawing on SCT and formats from past survey instruments to inform the design. Due to the exploratory nature of this research area, no existing validated survey tools were available for use.

Survey questions were designed and formatted with SCT as a guide. For instance, Likert-scale questions were designed to investigate how students' self-perceptions in social contexts affected their perceptions of their own learning or well-being, as below from Question 16:

"I would have learnt better by working alone."

"Having friends in my class makes me more motivated to learn."

The survey used question formats from validated survey tools from past studies of student perceptions of teaching and learning; questions were adapted appropriate to science fieldwork (Cotton, 2009; Dunphy \& Spellman, 2009; Peacock et al., 2018). Likert-scale questions allowed exploration of students' perceptions of, for instance, their social standing in a group or relationships with their peers. Open-response questions were included to allow students to express their opinions or rationales in their own words and to give context to the interpretation of quantitative results.

\section{Survey distribution and target demographic}

The survey was offered to undergraduate students undertaking biology units with repeated fieldwork (defined as fieldwork occurring at least every two weeks throughout the 12-week semester) within the Jock Marshall Reserve (JMR), an on-campus field site at Monash University. Units with non-repeating activities were omitted due to the reported 'novelty effect' of one-off fieldwork experiences (Peacock et al., 2018). The target units (see Table 1) offered an exploration of student perceptions across different units and year-levels.

Table 1. Target undergraduate units of questionnaire.

\begin{tabular}{cccc}
\hline Undergraduate Biology Unit & Unit Code & Year Level & Response Rate \\
\hline Environmental Biology & BIO1042 & $1^{\text {st }}$ & $14 \%(\mathrm{n}=36)$ \\
Conservation Biology & BIO2040 & $2^{\text {nd }}$ & $21 \%(\mathrm{n}=34)$ \\
$\begin{array}{c}\text { Environmental Sampling and } \\
\text { Monitoring }\end{array}$ & ENV2022 & $2^{\text {nd }}$ & $32 \%(\mathrm{n}=19)$ \\
Biology of Australian Vertebrates & BIO3132 & $3^{\text {rd }}$ & $29 \%(\mathrm{n}=25)$ \\
\hline
\end{tabular}

Many students undertaking $2^{\text {nd }}$ or $3^{\text {rd }}$ year units had previously undertaken the $1^{\text {st }}$ year unit $(34$ of 55 respondents). Whilst we found no significant quantitative difference in responses between year-levels or units, we recognise that respondents will have accrued differing levels of fieldwork experience during their course. However, due to the large number of options in a typical science degree, it is unlikely any two students would have similar experiences across a course.

The survey was advertised to the target population through announcements on the University's learning management system and the Monash Biological Society Facebook page. Participation was voluntary, with gift cards $(\$ 100$ and $\$ 50)$ offered as a raffle prize for participants. The survey was approximately 10 minutes long to increase the response rate and reduce response 'fatigue'. Survey distribution occurred using SurveyMonkey (http://www.surveymonkey.com). 
Response rates varied across units (see Table 1). Not all questions were made compulsory in the survey, leading to differing response rates between questions, and potential bias as discussed below.

\section{Demographic data}

The questionnaire had a total of 107 responses, equating to an overall response rate of $19 \%$, noting there were uneven responses across some questions. The majority of students were female $(78 \%, 71$ students), with a median age of 20 years old. The biology undergraduate cohort has a similar majority of female students; hence this bias was expected. Almost all were studying full-time (93\%, 85 students). Most students were studying either a Bachelor of Science or a double degree that included a Bachelor of Science (for instance, Bachelor of Science and Bachelor of Commerce) (81\%, 74 students). Common majors included ecology and conservation biology (35\%, 31 students), zoology (34\%, 30 students) and environmental earth sciences $(20 \%, 18$ students).

\section{Data analysis}

Quantitative data was collated, and summary statistics were generated using Microsoft Excel (Version 16.0, 2018). To compare quantitative data between units and study disciplines, additional non-parametric ANOVAs were performed in RStudio (Version 1.1.456, 2018). No significant differences were identified, so these results were omitted; however, this may be a result of uneven samples across units. Qualitative data was analysed using NVivo (QSR International Ltd. Version 12, 2018). Open coding was used to sort individual responses into nodes and sub-nodes, to identify emergent recurring themes and specific ideas that students held. This allowed the formation of a descriptive framework from the raw data to use for further analysis (Khandkar, 2009). Initial coding was cross-examined, revised and corroborated by secondary coders.

\section{Results}

Almost all students (94\%, 65 of 69 responses) perceived the social interactions they experienced during undergraduate science fieldwork as valuable. Many rationales emerged, with no single dominant reason. Most students perceived long-term positive effects to their well-being (54\%, 42 of 73 responses) and/or cognition (69\%, 52 of 75 responses). These results are reported below in more detail.

\section{What are the dominant reasons that science students value social interactions in fieldwork?}

When asked if socialising with peers and staff during fieldwork was valuable, students' responses were mostly positive (94\%, 65 of 69 responses) (Figure 1). This question's response rate was $64 \%$ (69 of 107 participants). 


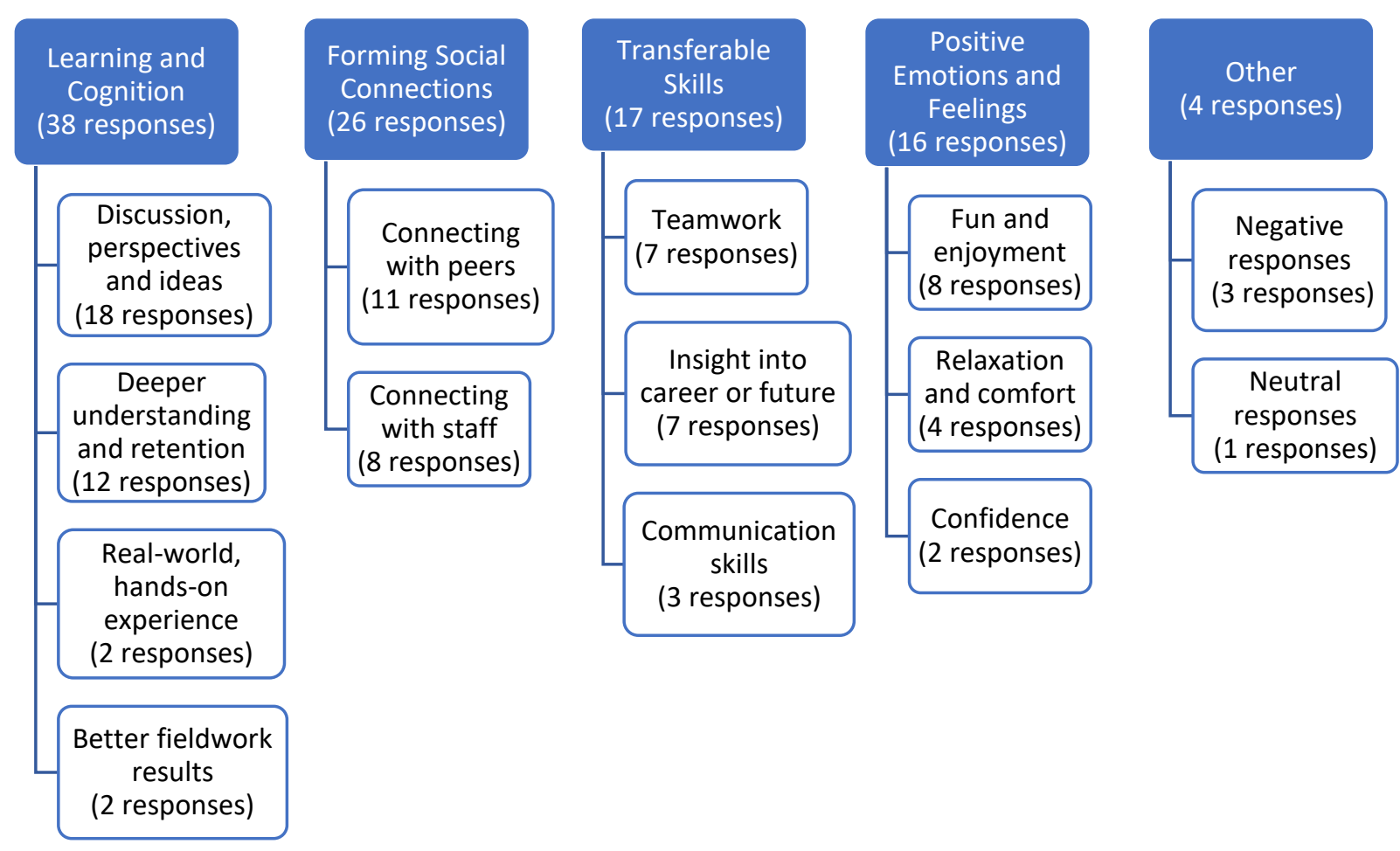

Figure 1. NVivo coding results of the open-response question 'Do you think that socialising with other students and staff is a valuable part of fieldwork? Why/why not?'. Blue boxes denote overarching themes and white boxes denote sub-themes.

Most commonly, social interactions were reported as valuable to areas of learning and cognition $(55 \%, 38$ responses; Figure 1). Students reported that fieldwork facilitated productive interactions, with benefits such as gaining different perspectives or ideas from peers $(26 \%, 18$ responses) or deeper conceptual understanding and information retention (17\%, 12 responses). For example:

"It allows you to discuss ideas and learn how to approach things from a different angle, one which you may not have previously considered." - Female, age 19, BIO2040

"Socialising with classmates benefits students, especially when you are able to discuss tricky concepts or need help with certain topics. ”- Female, age 20, BIO3132

The second most common theme was forming social connections (38\%, 26 responses). Students commonly reported that social interactions during fieldwork helped to form or deepen connections with peers $(16 \%, 11$ responses) or staff members (12\%, 8 responses). For instance:

"Building bonds with your classmates and teachers makes you feel more like a team." Female, age 19, BIO2040

Another common theme was developing transferable skills (25\%, 17 responses). Several students reported developing teamwork skills (10\%, 7 responses) and career insights $(10 \%, 7$ responses) as benefits of social interactions. As an example:

"Being able to communicate and work with others is a valuable skill that is highly valued by employers." - Female, age 20, BIO2132

Positive emotions and feelings were also a dominant theme (23\%, 16 responses). Students who reported benefits in this area perceived interactions in the fieldwork environment as enjoyable 
(12\%, 8 responses) and/or relaxing (6\%, 4 responses), with perceived positive influence on learning. For instance:

"It creates a comfortable environment to learn and enjoy yourself." - Female, age 21, BIO3132

Quantitative data supported these qualitative findings, with positive perceptions in similar themes emerging. (see Appendix, Table 2). Overall, our findings suggest the majority of students in the sample perceived social interactions during fieldwork as valuable and enjoyable, and linked this to more positive learning. There was no single dominant benefit, with a diverse range of rationales reported.

Do science students perceive that the social interactions in fieldwork benefit their wellbeing, and why?

When asked if they thought social interactions in fieldwork affected their well-being, more than half of respondents answered 'Yes' (57\%, 48 responses) (see Appendix, Table 3), all of whom perceived this effect to be positive. Many reported this effect was long-lasting, extending 'For the rest of the semester' (41\%, 20 responses) (see Appendix, Table 4).

Figure 2 shows themes that emerged when students were then asked the following openresponse question: 'Please explain how you think that the social dimensions of your work in the JMR had an effect on your well-being.' This question's response rate was 43\% (46 of 107 participants). The response rate is lower, potentially due to being later in the survey and noncompulsory.

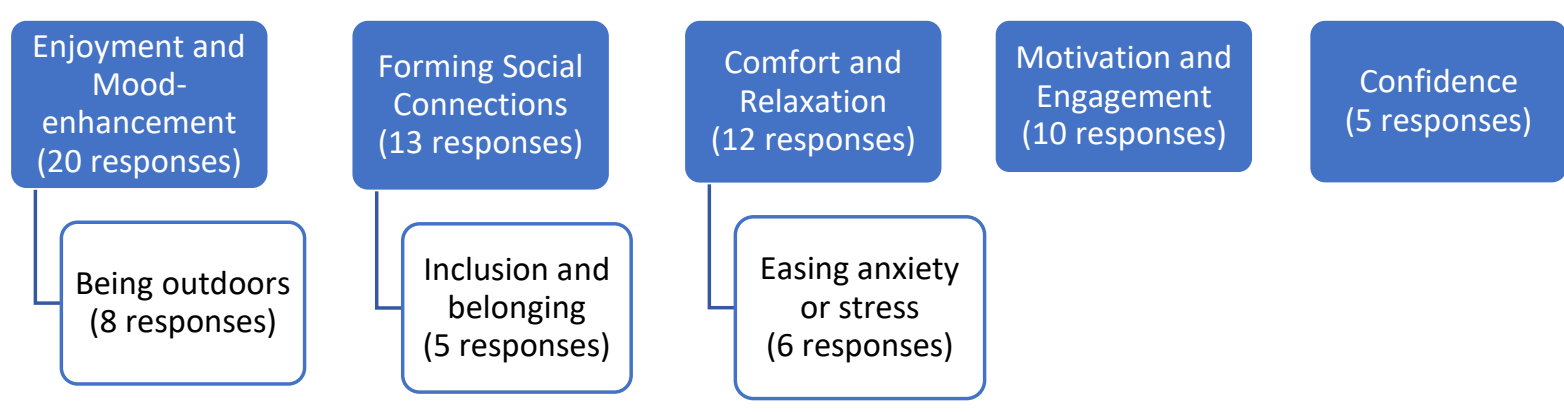

Figure 2. NVivo coding results of the open-response question 'Please explain how you think that the social dimensions of your work in the JMR had an effect on your wellbeing.' Blue boxes denote overarching themes and white boxes denote sub-themes.

Most commonly, students reported that social interactions during fieldwork improved their well-being because they made class activities more enjoyable (43\%, 20 responses; Figure 2), with several relating this to being outdoors in a natural environment (17\%, 8 responses). For example:

"The environment made me feel happy [...] I felt like I could connect with nature and my peers." - Female, age 21, BIO3132

Several students perceived well-being benefits through forming social connections $(28 \%, 13$ responses). Many reported a feeling of inclusion or belonging that would extend beyond the activity (11\%, 5 responses). For example: 
"I feel like the connections you make in lab classes or fieldwork transfer to other places like in lectures and has a positive impact on how you feel and engage in them." - Female, age 21, BIO3132

Another commonly perceived benefit to well-being among students was that social interactions made them feel generally more comfortable, positive and relaxed (26\%, 12 responses) or more specifically, students reported the environment helped reduce stress or anxiety $(13 \%, 6$ responses), as below:

"It made class more enjoyable and interesting, and made me less stressed about the work, so I was coming to those classes with a positive mindset." - Male, age 20, BIO2040

Another common theme was motivation and engagement (22\%, 10 responses). Sometimes this was related to retention. For example:

"It makes me more motivated to study because I am enjoying the task and have good memories of the topic." - Female, age 21, ENV2022

Again, the quantitative data supported the aforementioned qualitative findings (see Appendix, Table 5). Overall, both the qualitative and quantitative data suggested most students in the sample perceived social interactions during science fieldwork as having long-term benefits to their well-being.

Do science students perceive that social interactions in fieldwork benefit their cognition, and why?

When asked if socialising during fieldwork affected their cognition, most students answered 'Yes' (69\%, 60 responses) (see Appendix, Table 6). Of these students, almost all (98\%, 59 of 60 respondents) reported that this effect was positive. Many reported this effect as long-lasting, persisting 'For the rest of the semester' (57\%, 34 responses) (see Appendix, Table 7).

Figure 3 shows themes that emerged when students were asked the following open-response question: 'Please explain how the social dimensions of fieldwork had an effect on your cognition.' . This question's response rate was 56\% (60 of 107 participants). The response rate is lower than earlier open responses, potentially due to it being later in the survey and noncompulsory.

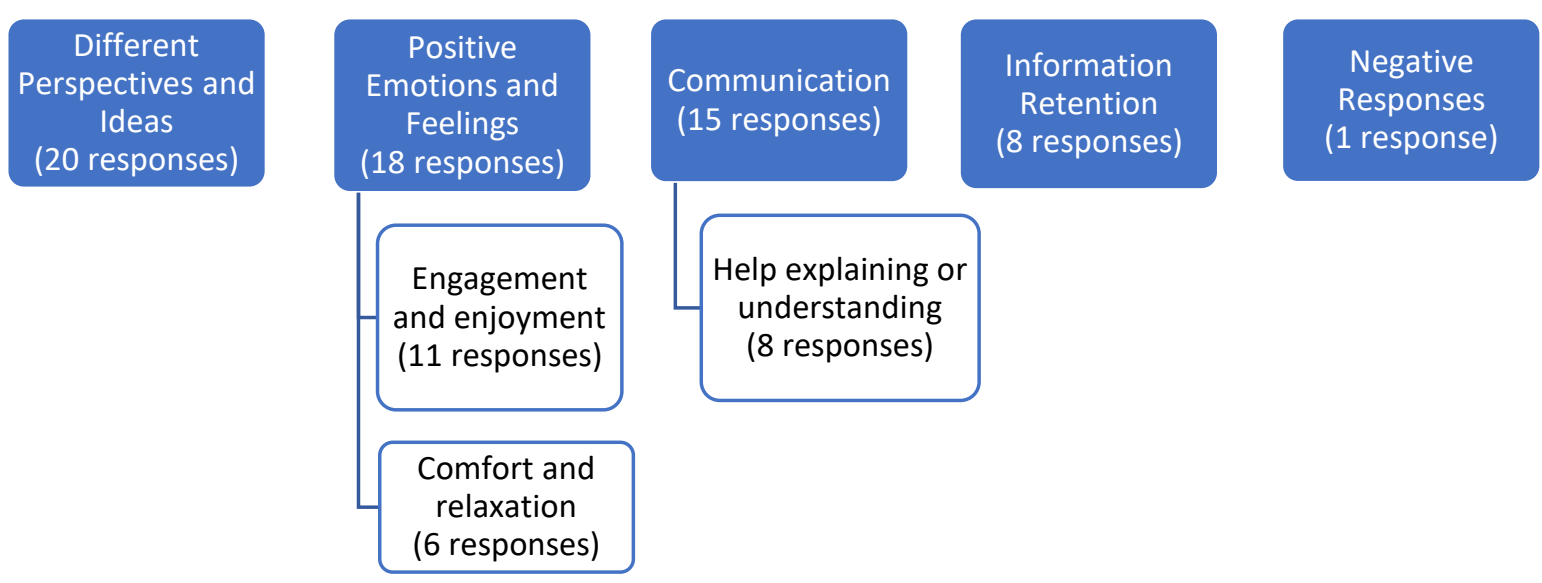

Figure 3. NVivo coding results of the open-response question 'Please explain how the social dimensions of fieldwork had an effect on your cognition.'. Blue boxes denote overarching themes and white boxes denote sub-themes. 
Most commonly, students perceived value in discussing material with people who had different perspectives and ideas (33\%, 20 responses; Figure 3). For example:

"Discussing things with other people allows for me to consider concepts and ideas from a different angle. It also allows for me to remember the things that are being discussed better in the future." - Female, age 21, BIO3132

Another common theme was positive emotions and feelings (30\%, 18 responses). Several students perceived that social interactions provided greater engagement with and enjoyment of the class $(18 \%, 11$ responses). For instance:

"... I feel more relaxed in the groupwork and tend to be more engaged in the work than if I've been in a group that doesn't interact and socialise with each other." - Female, age 20, $\mathrm{BIO} 3132$

Many students reported benefits to cognition through improved communication $(25 \%, 15$ responses), where interacting with peers was perceived as helpful for understanding concepts (13\%, 8 responses). For example:

"Socialising made me more perceptive to information that was communicated to us. I believe it allowed for better understanding of certain topics." - Female, age 20, ENV2022

Quantitative results again supported the emergent themes from the qualitative data providing a degree of triangulation (see Appendix, Table 8). Overall, the qualitative and quantitative data suggested that most students in the sample perceived that social interactions during science fieldwork had long-lasting benefits to cognition.

\section{Discussion}

\section{General perceptions of social interactions}

Students' responses to social interactions in fieldwork were overwhelmingly positive. This finding aligns with previous studies of undergraduate students in science and various other domains (Cotton, 2009; Dunphy \& Spellman, 2009; Goulder et al., 2013). Education researchers have reported benefits of social interactions to learning, social connections, professional development and positive emotions and feelings (Chanson, 2004; Goulder et al., 2013). Well-being benefits found in this study align with previous studies, including feeling socially connected, increased enjoyment and engagement (Burney, 2008; Matthews, Andrews, \& Adams, 2011). Commonly reported benefits to cognition in this study, such as improved conceptual understanding and information retention, corroborate with previous educational studies (Anderson et al., 2009; Scott et al., 2012). These benefits have not been collectively reported in a single fieldwork study before. Additionally, this study revealed a new potential benefit of social interactions to students, namely stress reduction, which is seldom discussed in the literature.

The diversity of responses illustrates the broad range of benefits social interactions could provide to the student experience, beyond the traditional research foci such as technical skill development. The overwhelmingly favourable perception of social interactions in this study implies positive affective responses in students overall, aligning with SCT and social learning principles in general. Boyle et al. (2007) posit that such affective responses would lead to deeper understanding of class material and improved learning outcomes. Thus, these results can help demonstrate how fostering positive emotions and feelings in students through experiences such as fieldwork can also lead to improved cognitive outcomes. This aligns with the key theory underpinning this study (Bandura 1986), and with the education objectives of 
the Australian Government to encourage students to form strong social connections that benefit their learning (DET, 2016; ESA, 2018).

\section{Perceived benefits of social interactions to well-being}

The majority of students in this study perceived social interactions during fieldwork as beneficial to their well-being. A variety of benefits to well-being were reported, supporting the findings of limited past science as well as some non-science studies. Several studies cited increased enjoyment and engagement as a benefit of fieldwork (Boyle et al., 2007; Goulder et al., 2013), and other studies discussed how fieldwork can augment student social connections (Chanson, 2004; Smith, 2004). However, the emerging themes of relaxation and stress reduction in our study are hitherto unmentioned themes in prior studies, indicating a potentially undervalued benefit of social interactions. Importantly, many students believed that these wellbeing benefits lasted for the rest of the semester. Several studies and reports highlight the longlasting benefits that supportive relationships can have to student motivation, engagement and commitment to their studies (Smith, 2004; ESA, 2018). This study's preliminary results could help to underline the potential long-term positive effects of fieldwork on the student experience, besides those traditionally reported benefits to academic performance and employability.

This study's results are encouraging when considering the aforementioned mental health issues facing universities (Gallagher, 2015). For instance, several students in this study perceived social interactions as helping them feel a sense of belonging, or in alleviating stress or anxiety. Educators could consider the potential for fieldwork to benefit students' mental well-being when designing educational activities, as highlighted by these results and those of past studies (Elias et al., 1997; Liff 2003). For example, utilising on-campus field sites to provide frequent recurring field activities and designing field tasks that emphasise collaboration could facilitate the formation of long-term supportive relationships, benefitting student well-being (Kent et al., 1997; Peacock et al., 2018).

Clearly, science students perceive that social interactions in fieldwork provide long-lasting benefits to their well-being. Given the focus on well-being in Australian education (DET 2016; ESA 2018), these results could be used to highlight the broader value of fieldwork in science undergraduate education and inform future research both domestically and internationally.

\section{Perceived benefits of social interactions to cognition}

Many of the commonly perceived benefits in this study aligned with previous findings in the literature. Boosted engagement, gaining different perspectives or ideas, and enhanced information retention are well-established outcomes of social interactions in fieldwork (Goulder et al., 2017; Scott et al., 2012). The recurring perception in this study that social interactions were helpful in understanding difficult concepts emphasises the value of educational concepts such as peer-to-peer learning (Burney, 2008) and social learning (Elias et al., 1997). Additionally, the recurring theme of increased relaxation and stress reduction suggests a newly found benefit to cognition, thereby adding further nuance to the topic of social interactions in education.

These results illustrate the potential link between student well-being and cognitive outcomes. Several dominant themes overlapped between the two contexts, such as increased motivation and engagement. Notably, in their open responses, many students in this study used their perceived benefits to well-being to rationalise their perceived benefits to cognition. For example, some students who perceived that social interactions enhanced their mood reported in later responses that this mood-enhancement lead to positive cognitive outcomes such as 
improved engagement. Studies in sociology and education literature have argued that optimising student well-being through social support can have added benefits to cognition (for examples see Boyle et al., 2007; Liff, 2003). Australian Government educational objectives also recognise the importance of the link between well-being and cognition in curriculum design (ACARA, 2020; DET 2016; ESA 2018). This study's results support the idea that fostering positive social interactions to promote science student well-being may also benefit their cognitive outcomes.

Educators could facilitate constructive social interactions by implementing fieldwork activities with allotted time for students to interact, resulting in stronger student relationships and improved learning outcomes. Several studies report that providing scheduled time for constructive social interactions during educational activities may benefit learning outcomes (Burney, 2008; Elias et al., 1997; Ingholt et al., 2015). Given students in this study perceived long-lasting benefits to cognition, this could lead to benefits both within the unit and potentially throughout the students' degree. Using fieldwork in undergraduate science could establish these long-lasting benefits early in a student's tertiary education, which may positively affect their long-term health and social development (Umberson et al., 2010).

In summary, students perceived many different long-lasting benefits of social interactions to cognition. Additionally, the results illustrate the perceived link between well-being and cognition in the student's view. Recognising the numerous benefits of fostering student wellbeing could help educators to design more effective undergraduate curricula that addresses both the well-being needs and cognitive outcomes of students, which are highly interrelated.

\section{Limitations}

As with all studies using self-reported data, there is a possibility of inherent bias. The responses may be inaccurate because of imperfect recollection or exaggerations (Connelly, 2013), and survey respondents may give an answer that they think the surveyor wants, rather than their honest answer (Paulhus \& Vazire, 2007). This must be kept in mind when assessing the applicability of the results of this study. However, the results of the open-responses are reinforced by the results of past studies and supported by quantitative data (see Appendix in Supplementary Material), creating some moderate triangulation.

The 'dose' effect of inconsistent field sessions could alter student perceptions through imperfect memory or changes unrelated to the course material, such as weather. To standardise the regularity of fieldwork, the selected units were chosen because they had recurring field sessions throughout the semester. Whilst no significant differences were found between year levels, $2^{\text {nd }}$ and $3^{\text {rd }}$ year students would likely have more previous fieldwork experience compared to $1^{\text {st }}$ year students. This difference must be considered; however, due to the flexibility of undergraduate science, no degree is identical and thus assessing a uniform student experience is challenging.

To increase total response rate, not all questions were compulsory, which led to different responses numbers between questions and units. This may affect the data's transferability. However, as the focus was the overall experiences and perceptions of undergraduate students in fieldwork, and not comparing particular units, the inclusion of multiple units was viewed as beneficial. Future study design should equalize response rates over all questions and potentially focus on only one unit or year level to provide more consistency of experience in the sample. Some terminology was inconsistent between survey questions, such as using 'social dimensions', 'socialising' and 'social aspects' interchangeably. The main terminology used in 
this paper, 'social interactions', was decided upon after survey design was completed. This inconsistency may have had a minor effect on this study's findings.

Last, the study took place in one institution and largely focused upon biology units. The transferability of the findings to other disciplines would need to be explored by incorporating further disciplines and tertiary science institutions. However, this study creates a foundation for a larger future study to take place and many of the results align with previous studies from field such as health and engineering.

\section{Implications for education design in and outside of fieldwork}

These preliminary results may allow educators to think more holistically about the value of fieldwork activities within a science degree. Fieldwork interactions have broad value to the overall degree experience, and potentially lead to student benefits such as improved well-being and inclusion with flow-on effects to learning. Future studies should further examine the mechanisms by which social learning in the field delivers benefits to students beyond technical skills. This may form a pathway forward for better identifying and leveraging these mechanisms in future to enhance learning and the student experience in undergraduate science. For example, allotting time in fieldwork for informal interactions could facilitate the formation of strong social connections. This may lead to greater feelings of belonging, community and engagement in students, and boost academic success by facilitating peer-to-peer learning (Matthews et al., 2011). Studies that experimented with allotting time for informal interactions reported benefits to student motivation, critical thinking and general well-being (Burney, 2008; Ingholt et al., 2015).

A possible approach for educators is to incorporate regular on-campus fieldwork into their science curriculum. This would reduce the 'novelty factor' of the field site, helping students focus on their learning while also facilitating informal social interactions. For instance, Peacock et al. (2018) implemented regular fieldwork in their undergraduate geography course, with students reporting both social and cognitive benefits. Furthermore, fieldwork in undergraduate science is largely in decline worldwide due to budgetary and logistical constraints, which may affect students' higher education experience (Da Silva, 2014; Smith, 2004). Using on-campus field sites would help to alleviate these constraints (Fleischner et al., 2017). This approach could have long-lasting benefits to student well-being, learning outcomes and skill development beyond the unit.

\section{Conclusions}

The results of this preliminary study suggest the broader value of science fieldwork as an educational tool, further unearthing how fieldwork is valuable to teaching and learning beyond its capacity to develop technical and employability skills. Despite varying response rates, students in our sample generally perceived social interactions as beneficial to both their wellbeing and cognition. These results align with the educational objectives of the Australian Government, emphasising the importance of cultivating student well-being in education while adding value in addressing the student perspective. This may be a growth area for future research, given the contemporary dilemma of youth health and an increasing focus by universities on student well-being. We hope this study sparks broader thinking about social learning in science and fieldwork, and prompts critical academic analysis to identify and categorise the complex and interconnected elements within the umbrella term of social interactions. Future studies should be undertaken to create more nuanced discussion in this area, and to help educators to identify and plan opportunities to optimise the educational benefits of science fieldwork. 


\section{Acknowledgements}

We would like to acknowledge all undergraduate participants from Monash University for completing this study's questionnaire. Special thanks to Camilla Fisher and Stephen Danczak for their valuable contributions to the secondary coding of qualitative data and to the manuscript. Thanks to Dave Chapple and his colleagues for their research that provided the framework for this study.

\section{References}

Anderson, D., Thomas, G. P., \& Nashon, S. M. (2009). Social barriers to meaningful engagement in biology field trip group work. Science Education, 93(3), 511-534.

Australian Curriculum, Assessment and Reporting Authority. (2020). Personal and Social Capability. Retrieved January 5, 2020, from https://www.australiancurriculum.edu.au/f-10-curriculum/generalcapabilities/personal-and-social-capability

Bandura, A. (1986). Social foundations of thought and action. Englewood Cliffs, NJ, 1986.

Boyle, A., Maguire, S., Martin, A., Milsom, C., Nash, R., Rawlinson, S., ... \& Conchie, S. (2007). Fieldwork is good: The student perception and the affective domain. Journal of Geography in Higher Education, 31(2), 299-317.

Burney, V. H. (2008). Applications of social cognitive theory to gifted education. Roeper Review, 30(2), 130139.

Chanson, H. (2004). Enhancing students' motivation in the undergraduate teaching of hydraulic engineering: Role of field works. Journal of Professional Issues in Engineering Education and Practice, 130(4), 259-268.

Chapple, D., Weir, B., \& San Martin, R. (2017) Can the Incorporation of Quick Response Codes and Smartphones Improve Field-Based Science Education? International Journal of Innovation in Science and Mathematics Education, 25(2).

Connelly, L. M. (2013). Limitation section. Medsurg Nursing, 22(5), 325-327.

Cotton, D. R. (2009). Field biology experiences of undergraduate students: the impact of novelty space. Journal of Biological Education, 43(4), 169-174.

Da Silva, K. B. (2014). Biological fieldwork in Australian higher education: Is the cost worth the effort?. International Journal of Innovation in Science and Mathematics Education, 22(2).

Department of Education and Training, (2016). Driving Innovation, Fairness and Excellence in Australian Higher Education. Retrieved from

https://docs.education.gov.au/system/files/doc/other/he_reform_paper_driving_innovation_fairness_and_exc ellence_3_may_2016.pdf

Dunphy, A., \& Spellman, G. (2009). Geography fieldwork, fieldwork value and learning styles. International Research in Geographical and Environmental Education, 18(1), 19-28.

Education Services Australia. (2019). Australian Student Wellbeing Framework. Retrieved from https://studentwellbeinghub.edu.au/media/9310/aswf_booklet.pdf

Edwards, K. J., Hershberger, P. J., Russell, R. K., \& Markert, R. J. (2001). Stress, negative social exchange, and health symptoms in university students. Journal of American College Health, 50(2), 75-79.

Elias, M. J., Zins, J. E., Weissberg, R. P., Frey, K. S., Greenberg, M. T., Haynes, N. M., ... \& Shriver, T. P. (1997). Promoting social and emotional learning: Guidelines for educators. ASCD.

Fleischner, T. L., Espinoza, R. E., Gerrish, G. A., Greene, H. W., Kimmerer, R. W., Lacey, E. A., ... \& Weisberg, S. (2017). Teaching biology in the field: importance, challenges, and solutions. BioScience, 67(6), 558-567.

Gallagher, R. P. (2015). National survey of college counseling centers 2014.

Goulder, R., Scott, G. W., \& Scott, L. J. (2013). Students' Perception of Biology Fieldwork: The example of students undertaking a preliminary year at a UK university. International Journal of Science Education, 35(8), 1385-1406.

Hodgson, Y., Bearman, M., \& Schneider-Kolsky, M. (2012) Lessons learned in implementing peer-assisted learning. International Journal of Innovation in Science and Mathematics Education, 20(3).

Ingholt, L., Sørensen, B. B., Andersen, S., Zinckernagel, L., Friis-Holmberg, T., Frank, V. A., ... \& Rod, M. H. (2015). How can we strengthen students' social relations in order to reduce school dropout? An intervention development study within four Danish vocational schools. BMC public health, 15(1), 502.

Kent, M., Gilbertson, D. D., \& Hunt, C. O. (1997). Fieldwork in geography teaching: A critical review of the literature and approaches. Journal of geography in higher education, 21(3), 313-332.

Khandkar, S. H. (2009). Open coding. University of Calgary, 23, 2009.

Kuchel, L, Wilson, R. S., \& Ellis, W. H. (2015) Cameras, competition and creativity: assessing $1^{\text {st }}$ year ecology in the field. International Journal of Innovation in Science and Mathematics Education 23(2), 34-45. 
Liff, S. B. (2003). Social and emotional intelligence: Applications for developmental education. Journal of Developmental Education, 26(3), 28.

Likert, R. (1932). A technique for the measurement of attitudes. Archives of psychology, 22(140), 55.

Matthews, K. E., Andrews, V., \& Adams, P. (2011). Social learning spaces and student engagement. Higher Education Research \& Development, 30(2), 105-120.

Paulhus, D. L., \& Vazire, S. (2007). The self-report method. Handbook of research methods in personality psychology, 1, 224-239.

Peacock, J., Mewis, R., \& Rooney, D. (2018) The use of campus based teaching to provide an authentic experience to all students. Journal of Geography in Higher Education, 42(4), 531-539.

Rayner, G (2014) A review of the value of prior learning in first year biology. International Journal of Innovation in Science and Mathematics Education, 22(2), 55-64.

Sadan, V. (2014). Mixed methods research: A new approach. International Journal of Nursing Education, 6(1), 254.

Scott, G. W., Goulder, R., Wheeler, P., Scott, L. J., Tobin, M. L., \& Marsham, S. (2012). The value of fieldwork in life and environmental sciences in the context of higher education: A case study in learning about biodiversity. Journal of Science Education and Technology, 21(1), 11-21.

Smith, D. (2004). Issues and trends in higher education biology fieldwork. Journal of Biological Education, 39(1), 6-10.

Umberson, D., Crosnoe, R., \& Reczek, C. (2010). Social relationships and health behavior across the life course. Annual review of sociology, 36, 139-157. 